\title{
STUDIES OF ANTIRICKETIC ACTIVITY IN SERA FROM PATIENTS WITH DISORDERS OF CALCIUM METABOLISM AND PRE- LIMINARY OBSERVATIONS ON THE MODE OF TRANSPORT OF VITAMIN D IN HUMAN SERUM *
}

\author{
BY WILLIAM C. THOMAS, JR., † H. GEMMELL MORGAN, $\ddagger$ THOMAS B. CONNOR, $\S$ \\ LILLIAN HADDOCK, $\|$ CHARLES E. BILLS AND JOHN E. HOWARD
}

(From the Johns Hopkins University and Hospital, Baltimore, Md.)

(Submitted for publication February 2, 1959; accepted March 5, 1959)

Proof of the curative action of vitamin $\mathrm{D}$ for rickets was established by the studies of many investigators $(1,2)$. It is now known that therapeutic doses of this vitamin bring about increased calcium absorption from the intestinal tract (3), while massive doses induce hypercalcemia (4) and, experimentally at least, a combination of skeletal resorption and vigorous bone-matrix formation (5-7). Also, in the hypoparathyroid individual, administration of vitamin $\mathrm{D}$ results in an increased excretion of phosphorus and usually of calcium $(8,9)$.

Knowledge of the biochemical or enzymatic means by which vitamin $\mathrm{D}$ induces the foregoing effects would greatly enhance our understanding of mineral and bone metabolism. An approach to the study of this problem was afforded by the reports of Warkany and his co-workers (10-12) on bioassays of vitamin $\mathrm{D}$ in sera of animals and humans. Vitamin D in aqueous solution, however, is known to be readily oxidized and thereby rendered inactive (13). This suggests that the vitamin, as it exists in serum, is in some manner protected and may not be in a free or unaltered state. Therefore, in our initial studies on vitamin

\footnotetext{
* The original work described in this paper was carried out under a contract between the United States Atomic Energy Commission and The Johns Hopkins University, and was supported in part by Grant No. A1913 from the Institute of Arthritis and Metabolic Diseases of the National Institutes of Health and in part by a gift from Mr. Lammot DuPont Copeland.

$\dagger$ Present address: University of Florida College of Medicine, Gainesville, Fla.

$\ddagger$ Present address: St. Andrews University Medical School, Queen's College, Dundee, Scotland.

§ Present address: University of Maryland School of Medicine, Baltimore, Md.

|| Trainee, National Institute of Arthritis and Metabolic Diseases.
}

$D$ it seemed pertinent to first survey the activity of this vitamin in the sera of patients having various disorders of calcium metabolism, and then to investigate its mode of transport and some of its physical properties as it exists in serum.

\section{METHODS}

Technique of bioassay. The amount of vitamin D normally present in serum is so small (10-12) that inconveniently large volumes of blood are required when bioassays are conducted by the usually recommended methods (14). It was determined that such requirements could be reduced by 1 ) designing a program of dosage inducing a maximum response from a minimum of serum, and 2) by utilizing a ricketogenic ${ }^{1}$ test diet which would result in uniformly severe rickets so as to lessen the number of test-failures requiring repetition. To meet these aims the following procedure was devised.

A colony of rats (Sprague-Dawley strain) was maintained in conformity with the general requirements of experimental rickets (14). The rats used for test purposes were weaned at a weight of 40 to $45 \mathrm{Gm}$. and were then fed the ricketogenic diet (Diet F, below) for 21 days. These rats were then put into individual cages and were given a special feeder containing the test substance. The feeder consisted of a tin pill box ( $50 \mathrm{~mm}$. wide) cemented into a Petri dish, the space between the rim of the box and the rim of the dish serving as a moat which minimized the loss of scattered food. Three $\mathrm{Gm}$. of Diet $\mathrm{F}$ and $0.2 \mathrm{ml}$. of maize oil were triturated in the pill box, and $2.0 \mathrm{ml}$. of serum, or serum diluted with water, was stirred in. Within an hour the test preparation formed a stiff gel which was difficult for the rat to scatter. Prompt consumption of the test substance was favored by presenting it in the late afternoon and it was usually eaten by the following morning. Rats not consuming all of the test material within 24 hours were discarded. Since the amount of food containing the serum for assay was less than half of the normal daily intake, such failures did not often occur. When reference solution of vita-

1 The etymology of this term has been discussed in footnote 1, Reference 13, and the recommended spelling has been adhered to in this article. 
min D (U.S.P. Reference Standard) was employed, it was given in like manner, i.e., in the $0.2 \mathrm{ml}$. of maize oil plus $2.0 \mathrm{ml}$. of water triturated with $3.0 \mathrm{Gm}$. of Diet F. Rats eating the assay mixture within the requisite 24 hours were then maintained on the ricketogenic Diet $\mathrm{F}$ until time of sacrifice.

It was found that good responses could be obtained in a total test period of five days (one day of vitamin D or serum supplementation followed by four days on plain Diet $\mathrm{F}$ ad libitum). All assays reported herein were done on this basis. The tibiae of the rats were examined for healing rickets after staining with silver in accordance with the usual line test technique and the degree of healing was assessed on a scale of five degrees as previously described (14). The curative action of the sera tested was evaluated by determining the amount of vitamin $\mathrm{D}$ required to induce the same healing effect. It has been our experience that with Diet F, employed as described, an assay of human serum can be performed with approximately half as much serum as would have been required in a conventional assay of comparable accuracy. The assay method utilized in this study permitted the detection of as little as one unit, or $0.025 \mu \mathrm{g}$., of vitamin $\mathrm{D}$.

Ricketogenic Diet $F$. The diet used was of the following composition ( $\mathrm{Gm}$. per $\mathrm{Kg}$. of diet) : maize starch, 500 ; dextrose (hydrous), 200 ; fibrin ${ }^{2}$ (extracted with hot alcohol), 150; dried yeast (Torula ${ }^{3}$ or brewer's ${ }^{4}$ ), 40 ; precipitated calcium carbonate, 30 ; salt mixture, 510 ; vitamin A palmitate in maize oil (100 I.U. per ml.), 70.

All ingredients were of sufficient fineness to pass through a 40-mesh sieve. The maize oil was added to the other components during slow, mechanical mixing and the diet, blended in $6 \mathrm{Kg}$. quantities, was stored under refrigeration.

Diet $\mathrm{F}$ is nutritionally complete except for a deficiency in phosphorus. The rickets induced in 21 days on this diet is much more severe and more uniform than that produced in the same period by use of conventional ricketogenic diets. The metaphyses are wide, free of calcified spots and rarely show cupping.

Serum. Serum not subjected to bioassay on the day of withdrawal was, except as noted below, kept in the frozen state until use.

Permeability studies. Ultrafiltration of serum was conducted according to a previously published technique (15) and both the ultrafiltrate and residue were assayed for antiricketic activity. Visking cellophane tubing was used to contain the serum during 48 hours dialysis against physiologic saline at $4^{\circ} \mathrm{C}$.

Electrophoresis. Electrophoresis of serum was conducted with starch blocks $(10 \times 45 \times 0.5 \mathrm{~cm}$. $)$ at $4^{\circ} \mathrm{C}$.

2 General Biochemical, Inc., Chagrin Falls, Ohio.

3 Rhinelander Paper Company, Rhinelander, Wisc.

4 Anheuser-Busch, Inc., St. Louis, Mo.

5 The salt mixture consisted of $(\mathrm{Gm}$. per $\mathrm{Kg}$. of mixture) : iodized table salt, 500; potassium chloride, 440; ferric phosphate, 20 ; magnesium carbonate, 20 ; manganese sulfate (dried). 17: cupric sulfate (anhydrous), 3 .
TABLE I

Antiricketic activity of serum from hypoparathyroid patients receiving vitamin $D_{2}$

\begin{tabular}{lcccc}
\hline \hline Patient & $\begin{array}{c}\text { Daily dose } \\
\text { of } \mathbf{D}_{\mathbf{2}}\end{array}$ & $\begin{array}{c}\text { Duration } \\
\mathbf{R x}\end{array}$ & Serum Ca & Assay \\
\hline & $($ I.U. $)$ & & $(\mathbf{m g} . \%)$ & $($ I.U./ml. $)$ \\
E.P. & 50,000 & 1 yr. & 9.5 & 40 \\
A.M. & 50,000 & 2 yrs. & 8.4 & 40 \\
L.L. & 100,000 & 6 mos. & 10.6 & 30 \\
A.C. & 100,000 & 5 yrs. & 10.0 & 48 \\
M.R. & 100,000 & 2 yrs. & 9.1 & 50 \\
H.C. & 200,000 & 15 mos. & 9.6 & 18 \\
L.C. & 200,000 & 3 yrs. & 8.6 & 8 \\
\hline
\end{tabular}

(16). Four ml. of serum containing a small amount of bromphenol blue and $1 \mathrm{ml}$. of barbital buffer was carefully placed near one end of the starch block. Under the conditions maintained (constant power source of $350 \mathrm{~V}$. and $30 \mathrm{ma}$.) a $40 \mathrm{~cm}$. migration of the serum was obtained in 38 to 40 hours. The starch block was then divided into $1 \mathrm{~cm}$. strips which were placed in individual centrifuge tubes containing $3 \mathrm{ml}$. of cold 0.9 per cent $\mathrm{NaCl}$. The contents of each tube were immediately mixed, centrifuged and the supernatant liquor was analyzed for concentration of protein (17). The remainder of the liquor was frozen for subsequent bioassay.

\section{RESULTS}

\section{Normal and hypoparathyroid subjects}

The sera of 18 normal subjects were assayed and found to contain between 0.7 and 3.1 I.U. of antiricketic activity per $\mathrm{ml}$. (mean of 2.0 I.U. per ml.). These results are essentially in agreement with those previously reported by Warkany and his associates (10-12). Hypoparathyroid patients receiving 50,000 to 200,000 I.U. of vitamin $\mathrm{D}_{2}$ daily had much more antiricketic activity in their sera, from 8 to 50 units per $\mathrm{ml}$. (Table I). However, as is evident from the results recorded in Table I, the amount of antiricketic activity existing in the sera of these patients could not be accurately predicted from either the dose of vitamin $D$ or the concentration of calcium in the serum.

It is known that persons given large doses of vitamin $\mathrm{D}$ have, after cessation of dosage, a slow decline in their serum activity (10-12). Observations on two of our subjects illustrate the variation which may occur in the persistence of serum antiricketic potency. One D-intoxicated patient with 30 units per $\mathrm{ml}$. in her serum still had an activity equivalent to 6 units per $\mathrm{ml}$. 
seven months after D administration was stopped. Another patient intoxicated by vitamin $\mathrm{D}$ and with a serum calcium concentration of $15 \mathrm{mg}$. per $100 \mathrm{ml}$. had an activity of only 8.5 units of vitamin $\mathrm{D}$ per $\mathrm{ml}$. of serum. In this latter patient the serum concentration was normal (2 I.U. per ml.) two and a half months after cessation of vitamin therapy. The slow decrease in antiricketic activity of serum subsequent to prolonged dosage with vitamin $\mathrm{D}$ is to be compared with the rate of increase in serum activity on institution of the vitamin. When to a normal subject 100,000 I.U. of $\mathrm{D}_{2}$ was given orally per day, the increase in serum activity was detectable within eight hours (activity increased by 2 I.U. per ml.), and at one week with continued dosage the serum $\mathrm{D}$ concentration was found to be equivalent to 14 units per $\mathrm{ml}$. These and the previously cited observations are in keeping with clinical evidence that vitamin $\mathrm{D}$ is a cumulative drug (9).

\section{Hypercalcemic subjects}

Sera from patients having hypercalcemia in association with a variety of disorders were subjected to bioassay. As was to be expected the sera from three patients with hyperparathyroidism had a normal vitamin D content. Similarly, the antiricketic activity of sera from eight patients having hypercalcemia in association with various neoplastic diseases (carcinoma of the lung, multiple myeloma and undifferentiated carcinoma of the pelvis) was also normal. Likewise, serum obtained from a single patient hypercalcemic with the milk-alkali syndrome did not contain an increased amount of vitamin D.

TABLE II

Antiricketic activity of serum in nontropical sprue

\begin{tabular}{|c|c|c|c|c|c|}
\hline \multirow[b]{2}{*}{ Patient } & \multirow[b]{2}{*}{ Therapy } & \multirow[b]{2}{*}{ Date } & \multicolumn{2}{|c|}{ Serum } & \multirow[b]{2}{*}{ Assay } \\
\hline & & & $\mathrm{Ca}$ & $\mathbf{P}$ & \\
\hline & & & $\begin{array}{l}(m g . \\
\%)\end{array}$ & $\underset{\%}{(m g})$ & $\underset{m l .}{(I . U . /}$ \\
\hline M.S. & $\begin{array}{l}\text { None } \\
\text { Cortisone \& Ca }\end{array}$ & $\begin{array}{l}2 / 6 / 54 \\
5 / 24 / 56\end{array}$ & $\mathbf{5 , 2}$ & $\begin{array}{l}1.3 \\
5.0\end{array}$ & $\begin{array}{l}1.1 \\
0.5\end{array}$ \\
\hline \multirow[t]{2}{*}{ M.T. } & $\begin{array}{l}\text { None } \\
\text { Cortisone (1 wk.) \& Ca } \\
\text { Cortisone \& 150,000 I.U. } \\
\mathrm{D}_{2} / \text { day for } 3 \text { mos. }\end{array}$ & $\begin{array}{l}2 / 5 / 57 \\
2 / 19 / 57 \\
5 / 21 / 57\end{array}$ & $\begin{array}{l}4.5 \\
6.9 \\
8.0\end{array}$ & $\begin{array}{l}2.4 \\
1.6 \\
3.6\end{array}$ & $\begin{array}{l}0 \\
0.7 \\
1.3\end{array}$ \\
\hline & $\begin{array}{l}\text { Cortisone \& } 150,000 \text { I.U. } \\
\mathrm{D}_{2} / \text { day for } 7 \mathrm{mos} \text {. }\end{array}$ & $9 / 10 / 57$ & 5.7 & 3.9 & 1.3 \\
\hline M.Q. & $\begin{array}{l}\text { Cortisone \& } 100,000 \text { I.U. } \\
D_{2} \text { for } 2 \text { yrs. } \\
\text { No } D_{2} \text { for } 6 \text { wks. }\end{array}$ & $\begin{array}{l}3 / 15 / 56 \\
8 / 10 / 56\end{array}$ & $\begin{array}{l}9.8 \\
8.6\end{array}$ & $\begin{array}{l}2.9 \\
3.7\end{array}$ & $\begin{array}{r}31 \\
7\end{array}$ \\
\hline
\end{tabular}

Idiopathic hypercalcemia of infants has many clinical similarities to D intoxication and is apparently not an uncommon disorder in England where milk is more heavily fortified with vitamin $\mathrm{D}$ than it is in the United States. This serious malady has been suspected to be due to vitamin D intoxication (resulting from excessive intake or possibly increased sensitivity) (18-20), and it has been recently reported that three infants with this disorder had much increased concentrations of antiricketic activity in their sera (21). However, the lyophilized samples of sera (unaltered sera was not available) from two such hypercalcemic infants tested by us contained normal quantities of antiricketic substance (vide infra). Similar assay results were obtained with the sera from three patients having hypercalcemia in association with sarcoidosis, a disorder in which the suggestion of increased sensitivity to vitamin $\mathrm{D}$ has also been made $(22,23)$.

It is known that cortisone promptly reduces the hypercalcemia of most D-intoxicated persons and also that due to a number of other causes (24-26) (except, in our experience, hyperparathyroidism and lung carcinoma). In two hypoparathyroid patients made hypercalcemic with vitamin $\mathrm{D}$, cortisone administration restored the serum calcium to normal, but not to the original hypocalcemic concentrations. Despite this decrease in calcium concentration the $\mathrm{D}$ content of the sera from these two patients remained unchanged by the cortisone. Such observations do not elucidate the means by which cortisone lessens hypercalcemia, but they are consistent with experimental studies indicating that vitamin $\mathrm{D}$ and cortisone have independent effects on bone (2729).

\section{Patients with nontropical sprue}

Evidence exists of defective absorption of fat soluble vitamins in patients with nontropical sprue (30). Moreover, hypocalcemia is not infrequently present (31). In Table II are recorded the data on three patients with this disorder. Patient M.S. had marked hypocalcemia despite a normal amount of vitamin D in her serum. Patient M.T. had a barely detectable amount of $\mathrm{D}$ in her serum prior to vitamin administration, with only a slight increase in serum antiricketic activity after pro- 
longed dosage with large amounts of vitamin $\mathrm{D}$. Moreover, even though attaining a normal amount of $\mathrm{D}$ activity in her serum, she remained hypocalcemic. The third patient (M.Q.) developed mild hypocalcemia (with normal serum proteins) in the face of a rather high concentration of antiricketic activity persisting in her serum after cessation of $\mathrm{D}$ therapy. Thus, factors other than vitamin D deficiency must have been responsible for the hypocalcemia in these patients.

\section{Physical properties of antiricketic substance in serum}

Sera from a number of subjects were assayed immediately after separation from blood and again after being in the frozen state for various periods. The results of these studies indicated that there was no loss of activity of sera kept frozen for intervals up to one year. Moreover, additional observations demonstrated that maintenance of sera at room temperature for as long as three days prior to assay did not result in any loss of antiricketic potency.

Ultrafiltrates of three sera were found to be free of antiricketic activity whereas the nonultrafiltrable portions contained all the activity present in the original sera. Assays of the residue and ultrafiltrate of one sample of serum to which vitamin $D_{8}$ (in propylene glycol) had been added in vitro (500 I.U. to $20 \mathrm{ml}$. serum) gave similar results in that here, too, all of the vitamin D activity remained in the nonfiltrable fraction. Studies on serum from another patient receiving large amounts of vitamin $D_{2}$ revealed that the antiricketic substance was also nondialyzable.

Warkany (10) has reported that lyophilized serum maintained at $-20^{\circ} \mathrm{C}$. retained all of its antiricketic potency. Using similarly treated sera which were reconstituted immediately prior to assay, we were able to confirm these observations. However, other studies which we have not yet completed suggest that in such reconstituted sera the antiricketic substance is not nearly so stable as in original sera. It is possible that loss of activity from lyophilized sera kept at room temperature accounted for the normal values obtained by us in hypercalcemic infants whereas others (21) have reported increased activity in such infants.

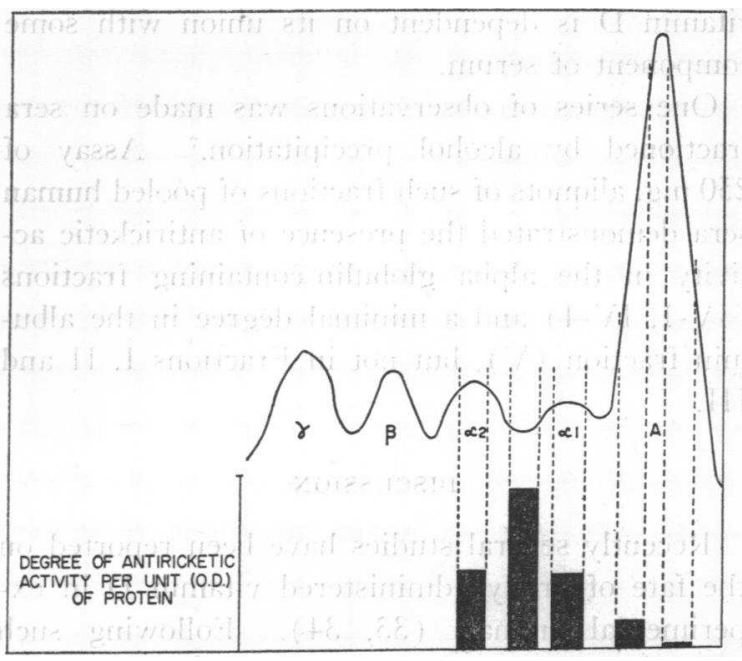

Fig. 1. Correlation of Antiricketic Activity with Amount of Protein Present in Individual fractions OF SERUM

\section{Localization of antiricketic substance in serum}

Sera from seven patients treated with large doses of calciferol were subjected to starch block electrophoresis. When eluates of the starch strips were fed to test rats, the antiricketic activity was located predominantly in the area of the alpha globulins and to a lesser degree in the albumin fraction; none was found to be with the slower moving globulins. Quantitation of the antiricketic effect (Figure 1) indicated that the greatest activity per unit of protein was in the area of the nadir between alpha 1 and alpha 2 globulin; next, in the alpha 1 and alpha 2 globulin-containing fractions; and least, in the albumin fraction.

To explore further the mode of transport of vitamin D, normal serum to which 500 I.U. of vitamin $D_{3}$ in propylene glycol had been added in vitro was also subjected to starch block electrophoresis. The location of the antiricketic activity was the same in this serum as in the sera from patients given the vitamin orally. In addition, we were unable to locate any antiricketic activity in starch strips after attempted electrophoresis of vitamin $D_{3}$ in propylene glycol alone. ${ }^{\circ}$ Therefore, it is probable that the electrophoretic mobility of

- Whether this lack of activity was a result of migration of $D_{3}$ off the starch block or of inactivation is not known. 
vitamin $\mathrm{D}$ is dependent on its union with some component of serum.

One series of observations was made on sera fractioned by alcohol precipitation. ${ }^{7}$ Assay of $250 \mathrm{mg}$. aliquots of such fractions of pooled human sera demonstrated the presence of antiricketic activity in the alpha globulin-containing fractions (IV-1, IV-4) and a minimal degree in the albumin fraction (V), but not in Fractions I, II and III.

\section{DISCUSSION}

Recently several studies have been reported on the fate of orally administered vitamin D in experimental animals $(33,34)$. Following such administration only a small fraction (10 to 30 per cent) of the dose could be recovered, the major portion having been destroyed, presumably within the intestinal lumen. It has been suggested that oxidation of the $\mathrm{D}$ vitamins within the gut may account for their disappearance after oral dosage and that the bacterial flora of the gut may be the responsible agents $(33,34)$. In one test of this possibility succinylsulfathiazole was fed to a group of rats prior to $\mathrm{D}$ administration, but this did not result in any improved recovery of the vitamin (35).

The results obtained on human subjects in the present experiments and previously, also, by Warkany (10-12) are consistent with the findings of Cruickshank and his co-workers (33-35). We found that ingestion of large doses of vitamin $\mathrm{D}$ were required to increase appreciably the antiricketic activity of the serum. Indeed, in the patients with hypoparathyroidism treated with vita$\min \mathrm{D}$ the lowest potency was found in the sera of those receiving the largest amount of vitamin (H.C. and L.C. of Table I). We have no data as to whether or not the relatively low serum activity in these particular patients resulted from poor absorption or from excessive destruction of the vitamin. Relevant to the possibility of increased destruction is the report of several patients given oral doses of $20 \mathrm{mg}$. (800,000 I.U.) of vitamin $\mathrm{D}_{2}$ in whom almost no active vitamin was recovered from the feces on biological assay (36).

\footnotetext{
${ }^{7}$ Serum fractions prepared by alcohol precipitation (32) and kindly supplied by Dr. Kenneth L. Zierler.
}

All patients who became hypercalcemic on large doses of vitamin $\mathrm{D}$ had much increased concentrations of antiricketic activity in their sera, but in some of the treated patients even higher concentrations did not result in hypercalcemia. Increases in serum calcium concentration induced by vitamin $\mathrm{D}$ are known to be enhanced by immobilization of the patient and also by the ingestion of alkali or large amounts of calcium, but no such causes were recognized to account for the gradations in responsiveness of the above subjects.

There are a number of circumstances associated with hypercalcemia other than hypervitaminosis $\mathrm{D}$ and the normal values for vitamin D-like activity found in the sera of patients with some of these hypercalcemic states are not surprising. However, it should be emphasized that these sera did not contain abnormal quantities of antiricketic substance detectable with the rat. The method of assay used in these experiments consisted of a comparison of the antiricketic effect of test substance with the effects of known amounts of vitamin $\mathrm{D}$ in ricketic rats. One must recall that dihydrotachysterol has, in man, hypercalcemic effects approximately equal to those of calciferol mg. for mg. (37, 38), yet this compound is only $1 / 400$ (or less) as potent an antiricketic substance as calciferol when fed to the rat $(39,40)$. Thus, our data do not negate the possibility that some agents differing only slightly from vitamin D may at times be etiologically important in the genesis of hypercalcemia.

The data obtained on the three patients with nontropical sprue were of interest and suggest that even though absorption of the vitamin may be poor such a defect alone is not sufficient to explain the hypocalcemia in these patients. Calcium absorption is known to be impaired in patients with steatorrhea and this may be of such degree and duration as eventually to result in hypocalcemia (apparently occurring when the bones become unable to support adequately serum calcium concentration). The reduced calcium concentration in the sera of patients given an exchange resin for weeks or months may be an analogous situation $(41,42)$.

Presumptive evidence that the vitamin D-like factor of serum is intimately bound to certain 
macro-molecules is afforded by its stability in serum, its nonultrafiltrability and the characteristic electrophoretic mobility. Moreover, cellular activity is not required for the union of vitamin D with its carrier in serum. The specific components of serum, whether proteins, lipoproteins or other compounds bearing this antiricketic factor have not been determined, but it is noteworthy that most of the activity was located in an area which does not correspond to that of the peak concentrations of either alpha 1 or alpha 2 lipoproteins (43). ${ }^{8}$

Little is known of the biochemical processes whereby vitamin $\mathrm{D}$ affects calcium absorption or bone metabolism. The vitamin has been reported to inhibit anaerobic glycolysis (45) and to enhance cocarboxylase formation (46). Also, it apparently retards oxidation of citrate to $\alpha$-ketoglutarate in the kidney but not in the liver (47, 48). These isolated biochemical observations do not distinguish direct from indirect effects of vitamin D and much more information is necessary to delineate the specific function of the vitamin as a coenzyme or necessary permissive agent in basic metabolic processes.

The observations reported herein on the antiricketic activity in serum, in addition to providing some insight into the variable response encountered on treating patients with vitamin $\mathrm{D}$, has been helpful in the investigation of a number of disorders of calcium metabolism. Moreover, demonstration that the vitamin is transported with specific fractions of the serum proteins in a stable and not readily oxidizable form may serve as a basis for future study of the chemical nature of the carrier substance and the state of vitamin D in serum.

\section{SUM MARY}

The mean antiricketic activity of sera from 18 normal subjects was found to be equivalent to 2 I.U. of vitamin D per ml. Hypoparathyroid patients receiving vitamin $\mathrm{D}_{2}$ had much increased activity in their sera, but the degree of activity could not be accurately predicted from either the dose of the vitamin or the induced increase in calcium concentration of the sera.

\footnotetext{
8 It should be noted that others (44), using a method difficult to assess, have reported binding of vitamin $D_{2}$ to protein fractions different from those suggested by us.
}

No increase in antiricketic effect was found in the sera of patients with various nonvitamin D-induced hypercalcemic states. Moreover, failure of vitamin $\mathrm{D}$ absorption alone did not account for the hypocalcemia in three patients with nontropical sprue.

The vitamin D activity of sera was found to be stable even at room temperature and was also nonultrafiltrable. On starch block electrophoresis the predominant antiricketic effect was limited to the area of the alpha globulins. The physical and electrophoretic characteristics were identical whether vitamin $\mathrm{D}$ was added to serum in vitro or in vivo.

\section{ADDENDUM}

Since submission of this manuscript additional studies have been conducted on the stability of reconstituted lyophilized sera. Assays of such sera revealed no loss of antiricketic potency after standing at room temperature for as long as three days. These observations suggest that the results obtained with lyophilized sera from hypercalcemic infants in Scotland are valid. Therefore, the assay data available, although limited, indicates that the genesis of the hypercalcemia in the Scottish children tested differs from that in the American infants reported by Fellers and Schwartz (21).

\section{REFERENCES}

1. Bills, C. E. Physiology of the sterols, including vitamin D. Physiol. Rev. 1935, 15, 1.

2. Eliot, M. M., and Park, E. A. Rickets in Brennemann's Practice of Pediatrics, I. McQuarrie, Ed. Hagerstown, Md., W. F. Prior Co., Inc., 1957, vol. I, Chapter 36.

3. Bauer, W., and Marble, A. Studies on the mode of action of irradiated ergosterol. II. Its effects on the calcium and phosphorus metabolism of individuals with calcium deficiency diseases. $\mathrm{J}$. clin. Invest. 1932, 11, 21.

4. Hess, A. F., Benjamin, H. R., and Gross, J. Source of excess calcium in hypercalcemia induced by irradiated ergosterol. J. biol. Chem. 1931, 94, 1.

5. Harris, L. J., and Innes, J. R. M. The mode of action of vitamin D. Studies on hypervitaminosis D. The influence of the calcium-phosphate intake. Biochem. J. 1931, 25, 367.

6. Ham, A. W., and Lewis, M. D. Hypervitaminosis D rickets: The action of vitamin D. Brit. J. exp. Path. 1934, 15, 228.

7. Follis, R. H., Jr. Studies on hypervitaminosis D. Amer. J. Path. 1955, 31, 568. 
8. Albright, F., and Reifenstein, E. C., Jr. The Parathyroid Glands and Metabolic Bone Disease. Baltimore, The Williams \& Wilkins Co., 1948, p. 127.

9. Howard, J. E., and Connor, T. B. Some experiences with the use of vitamin $D$ in the treatment of hypoparathyroidism. Trans. Ass. Amer. Phycns 1954, 67, 199.

10. Warkany, J. Estimation of vitamin D in blood serum. Amer. J. Dis. Child. 1936, 52, 831.

11. Warkany, J., and Mabon, H. E. Estimation of vita$\min \mathrm{D}$ in blood serum. II. Level of vitamin $\mathrm{D}$ in human blood serums. Amer. J. Dis. Child. 1940, 60,606 .

12. Warkany, J., Guest, G. M., and Grabill, F. J. Estimation of vitamin D in blood serum. J. Lab. clin. Med. 1942, 27, 557.

13. Bills, C. E. Chemistry of vitamin D group in The Vitamins, W. H. Sebrell, Jr. and R. S. Harris, Eds. New York, Academic Press Inc., 1954, vol. II, Chapter 6, Part II, p. 132.

14. Bills, C. E. Vitamin D assay-Line test and chemical methods. Biol. Symp. 1947, 12, 409.

15. Hopkins, T., Howard, J. E., and Eisenberg, H. Ultrafiltration studies on calcium and phosphorus in human serum. Bull. Johns Hopk. Hosp. 1952, 91, 1.

16. Kunkel, H. G. Zone electrophoresis in Methods of Biochemical Analysis, D. Glick, Ed. New York, Interscience Publishers, Inc., 1954, vol. I, p. 141.

17. Kunkel, H. G., and Tiselius, A. Electrophoresis of proteins on filter paper. J. gen. Physiol. 1951, 35, 89.

18. Lightwood, R. Idiopathic hypercalcaemia with failure to thrive: Nephrocalcinosis. Proc. roy. Soc. Med. 1952, 45, 401.

19. Creery, R. D. G., and Neill, D. W. Idiopathic hypercalcaemia in infants with failure to thrive. Lancet 1954, 2, 110.

20. Morgan, H. G., Mitchell, R. G., Stowers, J. M., and Thomson, J. Metabolic studies on two infants with idiopathic hypercalcaemia. Lancet 1956, 1, 925.

21. Fellers, F. X., and Schwartz, R. Etiology of the severe form of idiopathic hypercalcemia of infancy. New Engl. J. Med. 1958, 259, 1050.

22. Anderson, J., Dent, C. E., Harper, C., and Philpot, G. R. Effect of cortisone on calcium metabolism in sarcoidosis with hypercalcaemia. Possibly antagonistic actions of cortisone and vitamin $\mathrm{D}$. Lancet 1954, 2, 720.

23. Henneman, P. H., Dempsey, E. F., Carroll, E. L., and Albright, $F$. The cause of hypercalcuria in sarcoid and its treatment with cortisone and sodium phytate. J. clin. Invest. 1956, 35, 1229.

24. Dent, C. E. Cortisone test for hyperparathyroidism. Brit. med. J. 1956, 1, 230.

25. Connor, T. B., Hopkins, T. R., Thomas, W. C., Jr., Carey, R. A., and Howard, J. E. The use of corti- sone and ACTH in hypercalcemic states (abstract). J. clin. Endocr. 1956, 16, 945.

26. Verner, J. V., Jr., Engel, F. L., and McPherson, H. T. Vitamin $\mathrm{D}$ intoxication: Report of two cases treated with cortisone. Ann. intern. Med. 1958, 48, 765.

27. Harrison, H. C., Harrison, H. E., and Park, E. A. Vitamin $\mathrm{D}$ and citrate metabolism. Inhibition of vitamin $\mathrm{D}$ effect by cortisol. Proc. Soc. exp. Biol. (N. Y.) 1957, 96, 768.

28. Cruickshank, E. M., and Kodicek, E. The antagonism between cortisone and vitamin D: Experiments on hypervitaminosis D in rats. J. Endocr. 1958, 17, 35.

29. Thomas, W. C., Jr., and Morgan, H. G. The effect of cortisone in experimental hypervitaminosis D. Endocrinology 1958, 63, 57.

30. Volwiler, W. Gastrointestinal malabsorptive syndromes. Amer. J. Med. 1957, 23, 250.

31. Juergens, J. L., Scholz, D. A., and Wollaeger, E. E. Severe osteomalacia associated with occult steatorrhea due to nontropical sprue. Report of five cases. Arch. intern. Med. 1956, 98, 774.

32. Cohn, E. J., Strong, L. E., Hughes, W. L., Jr., Mulford, D. J., Ashworth, J. N., Melin, M., and Taylor, H. L. Preparation and properties of serum and plasma proteins. IV. A system for the separation into fractions of the protein and lipoprotein components of biological tissues and fluids. $\mathrm{J}$. Amer. chem. Soc. 1946, 68, 459.

33. Cruickshank, E. M., and Kodicek, E. Vitamin D balance and distribution in rats given a massive dose of ergocalciferol. I. Experimental results. Biochem. J. 1953, 54, 337.

34. Cruickshank, E. M., Kodicek, E., and Armitage, P. The vitamin D content of tissues of rats given ergocalciferol. Biochem. J. 1954, 58, 172.

35. Cruickshank, E. M., Kodicek, E., and Armitage, P. The effect of bacteriostatics on the metabolism of vitamin D. 3rd International Congress of Biochemistry. Resumés des communications, Brussels, 1955, p. 113.

36. Kodicek, E. Metabolic studies on vitamin D in Ciba Foundation Symposium on Bone Structure and Metabolism, G. E. W. Wolstenholme and C. M. O'Connor, Eds. Boston, Little, Brown and Co., 1956, p. 161.

37. Rose, E., and Sunderman, F. W. Effect of dihydrotachysterol in treatment of parathyroid deficiency. Arch. intern. Med. 1938, 64, 217.

38. Saville, P. D., Nassim, J. R., Stevenson, F. H., Mulligan, L., and Carey, M. The effect of A. T. 10 on calcium and phosphorus metabolism in resistant rickets. Clin. Sci. 1955, 14, 489.

39. Shohl, A. T., and Farber, S. Effect of A. T. 10 (Dihydrotachysterol) on rickets in rats produced by high-calcium-low-phosphorus diets. J. Nutr. 1941, 21, 147. 
40. Correll, J. T., and Wise, E. C. Antirachitic properties of A. T. 10 for the rat and chicken. J. Nutr. 1942, 23, 217.

41. Dock, W., and Frank, N. R. Cation exchangers. Their use and hazards as aids in managing edema. Amer. Heart J. 1950, 40, 638.

42. Greenman, L., Shaler, J. B., and Danowski, T. S. Biochemical disturbances and clinical symptoms during prolonged exchange resin therapy in congestive heart failure. Amer. J. Med. 1953, 14, 391.

43. Kunkel, H. G., and Slater, R. J. Lipoprotein patterns of serum obtained by zone electrophoresis. J. clin. Invest. 1952, 31, 677.

44. Troitskii, G. V., and Tarasova, L. S. The nature of blood protein complexes with carotene, vitamin A, vitamin $D_{2}$ and cholesterol. Biokhimiya 1955, 20, 19 (Chem. Abstracts 1955, 49, 9120).

45. Festenstein, G. N. The effect of ergosterol and ergocalciferol on the anaerobic glycolysis of ratliver slices. Biochem. J. 1955, 59, 605.

46. Räihä, C. E., and Forsander, O. Vitamin D and phosphorylation of thiamin. Acta paediat. (Uppsala) 1954, 43, Suppl. 100, 541.

47. DeLuca, H. F., Gran, F. C., and Steenbock, H. Vitamin D and citrate oxidation in rat kidney mitochondria. Fed. Proc. 1957, 16, 171.

48. DeLuca, H. F., and Steenbock, H. An in vitro effect of vitamin $D$ on citrate oxidation by kidney mitochondria. Science 1957, 126, 258. 